\title{
Article \\ A Modified Pressure-Sinkage Model for Studying the Effect of a Hard Layer in Sandy Loam Soil
}

\author{
Nihal D. Salman ${ }^{1,2, *}$, György Pillinger ${ }^{3}$, Muammel M. Hanon ${ }^{1,2, * \mathbb{D}}$ and Péter Kiss ${ }^{3}(\mathbb{C}$ \\ 1 Mechanical Engineering Doctoral School, Szent István Campus, MATE University, 2100 Gödöllő, Hungary \\ 2 Baquba Technical Institute, Middle Technical University (MTU), Baghdad, Iraq \\ 3 Institute of Technology, Hungarian University of Agriculture and Life Sciences (MATE), 2100 Gödöllo, \\ Hungary; pillinger.gyorgy@uni-mate.hu (G.P.); kiss.peter@uni-mate.hu (P.K.) \\ * Correspondence: salman.nihal.dawood@phd.uni-szie.hu (N.D.S.); \\ sharba.muammel.m.hanon@phd.uni-szie.hu (M.M.H.)
}

Citation: Salman, N.D.; Pillinger, G.; Hanon, M.M.; Kiss, P. A Modified Pressure-Sinkage Model for Studying the Effect of a Hard Layer in Sandy Loam Soil. Appl. Sci. 2021, 11, 5499. https://doi.org/10.3390/app11125499

Academic Editors: Lorena Parra and Pedro V. Mauri

Received: 21 May 2021

Accepted: 11 June 2021

Published: 14 June 2021

Publisher's Note: MDPI stays neutral with regard to jurisdictional claims in published maps and institutional affiliations.

Copyright: () 2021 by the authors. Licensee MDPI, Basel, Switzerland. This article is an open access article distributed under the terms and conditions of the Creative Commons Attribution (CC BY) license (https:// creativecommons.org/licenses/by/ $4.0 /)$.

\begin{abstract}
The applicability of the typical pressure-sinkage models used to characterize the soil's bearing properties is limited to homogeneous soils (infinite thickness) that have no hard layer. At a given depth, a hard layer can have a considerable impact on the soil's load-bearing capacity. It is thus necessary to alter the pressure-sinkage equation by taking this condition into account when assessing the load-bearing capacity. The present paper aims to determine a simple, high-fidelity model, in terms of soil characterization, that can account for the hard layer affection. To assess hard layer affection in this paper, a plate sinkage test (bevameter) was conducted on sandy loam soil. To this end, the soil was prepared by considering three bulk densities and two soil thickness levels at $7-9 \%$ moisture content levels. According to the results, this paper put forth a new perspective and related equations for characterizing bearing performance. The sinkage modulus $(\mathrm{k})$ is an intrinsic soil parameter that has a determined unit of $\mathrm{N} / \mathrm{cm}^{2}$ and is significant for managing the bearing performance. The results showed that the new modulus sinkage model incorporates the main factor of the rigid layer effect involving high fidelity that the conventional models have failed to account for.
\end{abstract}

Keywords: pressure-sinkage relationship; soil deformation; bevameter; sinkage modulus; loadbearing capacity

\section{Introduction}

In an off-road environment, the key factor impacting vehicle mobility and wheels' sinking and slipping is soil deformation [1-4]. The mechanical properties of the soil can restrict the traction of machine mobility [5,6]. The soil's mechanical properties can be classified as bearing properties in the normal direction and shearing in the tangential direction. Bearing involves pressure-sinkage (load carrying capacity) relationship equations [7-9]. When assessing a vehicles' mobility and traction on unstructured terrains, the pressure-sinkage relationship is crucial [10-13]. The pressure-sinkage model can indicate the soil strength or stiffness and is thus necessary in soil mechanics to establish the soil's stability and the extent to which it can deform [14]. Generally, there are two aspects to the sinkage process which are plastic deformation and elastic deformation. Plastic deformation tends to take place only in the case of very small loads. Hence, using the same model for determining the soil's sinkage characteristics is not feasible. Research on terramechanics commonly uses simplified models [15]. Several studies have tried developing empirical models through which the pressure-sinkage relationship can be characterized. These models assume that the soil from the surface to the required depth is homogeneous [16]. Typically, to verify pressure-sinkage models, experiments involving flat, rigid plates are used, and the parameters are established based on the results [7]. Bernstein and Goriatchkin were the first to put forth the earliest empirical model that could characterize the pressure-sinkage relationship for terrain [17]. Their model formed the basis for numerous improved models [7,18-21]. In 
1956, when Bekker observed that the plate's width or radius impacts the parameters, he put forth the Bekker model [22]. In this model, the dimensions of the parameters concerning the soil modulus rely on a sinkage exponent. Bekker's model was further improved upon in 1965 by Reece, who used two dimensionless parameters [23]. In 1959, Saakyan suggested a pressure-sinkage equation that was based on the Boussinesq theory regarding the elastic half-space indicated in Equation (1) [24].

$$
\mathrm{p}=\mathrm{k}\left(\frac{\mathrm{z}}{\mathrm{D}}\right)^{\mathrm{n}}
$$

where $\mathrm{p}$ is the average pressure under an indenter, D is the diameter of the indenter, $\mathrm{z}$ is the vertical soil deformation (sinkage), and $\mathrm{k}$ is the sinkage modulus (load-carrying capacity factor).

It is noteworthy that Equation (1) applies to homogeneous soils that do not have a hard layer; that is, there is a decrease in monotonic sinkage when ground pressure increases. In reality, vehicles tend to work in soils that have a hard layer, or hardpan, at a depth [25]. Because of the tillage operations and the resulting settling, varied local load-carrying capacities are generated at diverse depths. While the upper, loose layer's load-carrying capacity is low, the deeper layer's load-carrying capacity is based on the tillage operation, although it increases with depth. Boussinesq's theory states that there is a gradual reduction in the exerted surface pressure as a function of depth. At a given depth, if there is a rigid layer, it alters the pressure distribution as a function of relative depth [26]. An analytical pressure-sinkage model was presented by Ageikin that considered the soil hardpan effect $[27,28]$. In this model, the equation for assessing the soil's bearing capacities in terms of infinite hardpan does not apply to some types of soil. To address the Ageikin model's limitations, in 2010, Lyasko developed an analytical model by considering invariant soil parameters that are not impacted by other factors, including the plates' dimensions [25]. These are two complicated models that are difficult to apply. Egorov's model focused on the homogenous soil's stress and displacement of finite thickness foundation. This model can be applied for evaluating the deformation of a soil layer that is underlain by a hard layer with no compaction. According to this model, deformations under foundations, even with no underlying hard layer, focused on the massif's upper part and are not deeply entrenched. This leads to an "active zone", where the base can be considered deformed. It is crucial to consider the core depth problem when calculating the finite thickness base. This can only be experimentally addressed, as per the measurements of the building soil's layer-by-layer deformations [29].

Salman et al. examined the hard layer's affection on the sandy loam soil behavior and noted that the hard layer increased the pressure and compaction, thus altering the soil behavior. Moreover, it increased deformation and changed the pressure-sinkage equation parameters [30].

The present study aims to characterize the pressure-sinkage relationship that can indicate the soil's hard layer simply and in a general manner with meaningful parameters. The study also intends to specify the zone (breaking point) in which the rigid layer impacts the compaction. Further, the study presents a new way to characterize the pressure-sinkage relationship by altering the sinkage modulus (k) in Equation (1). However, there are certain problems when determining the sinkage modulus $\mathrm{k}$, and these problems can be caused by extreme variability in the soil textures, the distribution of the moisture content and its impact on the mechanical properties, and the hardness distribution in the hardpan at finite depth. Hence, large circular plates were used to ensure that the loading conditions were similar to those occurring in a real tire.

\section{Materials and Methods}

As shown in Figure 1a, a bevameter (plate sinkage test) was utilized to carry out the experiments. The equipment's design, construction, and function are explained in other published research [31]. 


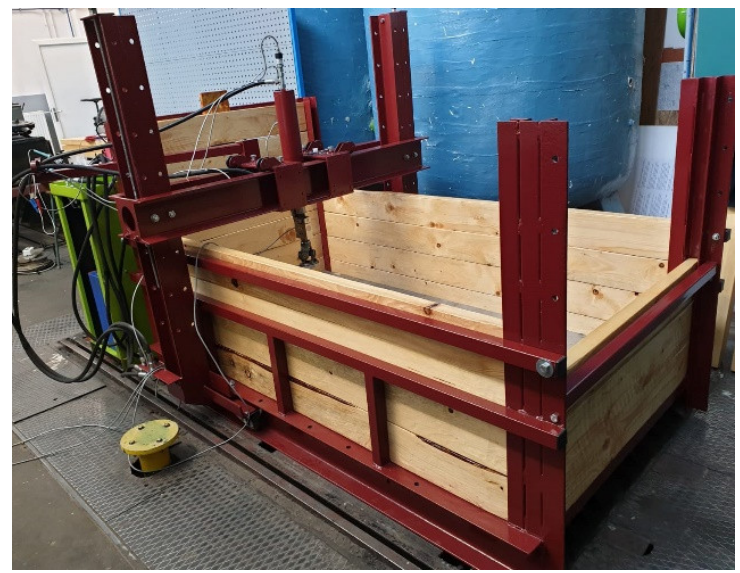

(a)

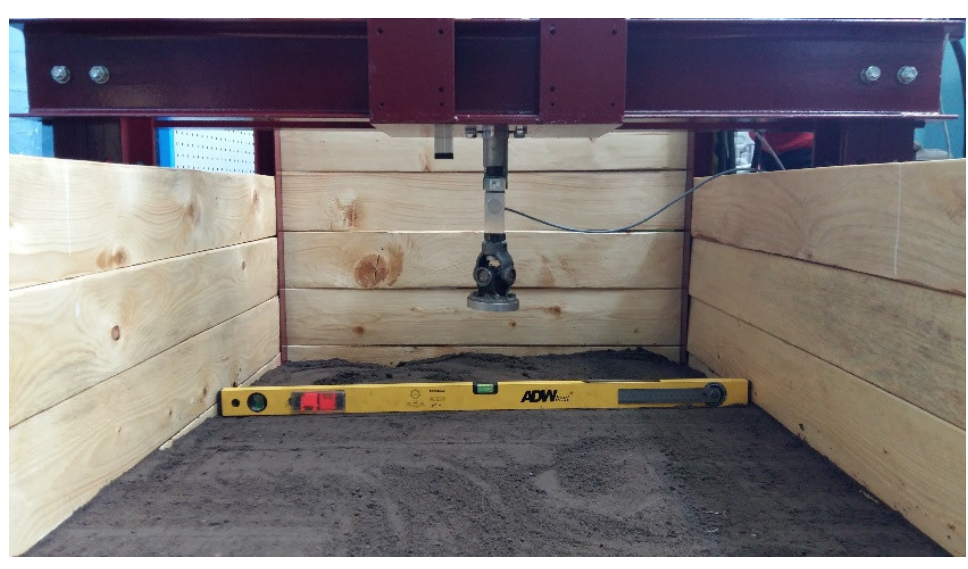

(b)

Figure 1. (a) Plate sinkage test (bevameter device); (b) soil surface leveling.

A hydraulic cylinder was used to apply the necessary load. The experiment included a soil bin that was $200 \mathrm{~cm}$ in length, $100 \mathrm{~cm}$ in width, and had a changeable thickness of $70 \mathrm{~cm}$. Three circular sinkage plates of $10 \mathrm{~cm}, 15 \mathrm{~cm}$, and $20 \mathrm{~cm}$ are connected to the hydraulic cylinder and are in contact with the soil. A known force is applied to this soil. The applied vertical load is measured through using a stainless-steel S-beam load cell (HBM, Germany) with a $30 \mathrm{kN}$ capacity. To measure the vertical deformation (sinkage), an analog displacement encoder (MLO-POT-0360-TLF, FESTO, Germany) with a $30 \mathrm{~cm}$ stroke was used. This displacement sensor's slider was connected to the hydraulic cylinder rod end and was simultaneously moving. The hydraulic cylinder could move transversely as well as longitudinally through the rail to test all points in the soil bin's soil surface. The soil bin's bottom was a hard layer in a field. The tilling of agricultural soils is performed until $30-40 \mathrm{~cm}$ of depth, which is similar to the contact diameter of tires [24]. The soil thickness can be assessed because the soil bin's height can be changed.

To prepare the soil: first, the soil (from a field belonging to the Szent István Campus, MATE University, Hungary) was transferred to the laboratory; then, a $5 \mathrm{~mm}$ mesh was used to sieve this soil and remove any coarse parts and plant roots; and the soil was then stored where it would not dry up. Previous studies have used this same soil [32,33], which is a sandy loam with a composition of sand $(2-0.05 \mathrm{~mm})$, mud $(0.05-0.002 \mathrm{~mm})$, and clay $(<0.002 \mathrm{~mm})$. The soil's bulk density and moisture content can be established using the sampling method, which involves taking different soil samples during and after the tests. The soil samples were dried for $24 \mathrm{~h}$ in the oven at $110^{\circ} \mathrm{C}$. The weight of the samples was noted before and after drying them to establish the moisture content and bulk density. Table 1 presents the soil examination results, along with the angle of shearing resistance and the cohesion that was determined based on the direct shear test results.

Table 1. Mechanical properties of sandy loam soil used in the experiments.

\begin{tabular}{cc}
\hline Feature & Value \\
\hline Cohesion & $58.07 \mathrm{kPa}$ \\
Angle of shearing resistance & $37.59^{\circ}$ \\
Water content & $7-9 \%$ dry basis \\
Bulk density & $1.3,1.4$, and $1.5 \mathrm{~g} / \mathrm{cm}^{3}$ \\
\hline
\end{tabular}

The tests were conducted in a laboratory under controlled conditions. For the tests, two soil thicknesses of $30 \mathrm{~cm}$ and $40 \mathrm{~cm}$ were used with diverse bulk densities. The soil bin was first filled with $30 \mathrm{~cm}$ thickness of soil in layers, with each layer being $5 \mathrm{~cm}$ thick. A wood plate was used to compress all layers and obtain the initial bulk density of $1.3 \mathrm{~g} / \mathrm{cm}^{3}$. 
To avoid the concentration of stress on conglomerated points at the soil surface under the loading plate, the soil surface was specifically leveled, as shown in Figure 1b. To apply the load, a sinkage plate with a $20 \mathrm{~cm}$ diameter was used, as this size offers more realistic conditions that would be comparable to the soil's behavior under a tire. Next, the sinkage plate was connected to the force sensor and moved closer to the soil surface through the bevameter. The S-beam load cell was used to measure the vertical force, and the analog displacement encoder was used to measure the displacement. These steps were conducted at the sinkage plate's $3 \mathrm{~cm} / \mathrm{s}$ penetration rate. The penetration points were obtained where the soil bin walls would not impact the data. The force and displacement sensors transferred the signals to a strain gauge measurement device, called Spider 8, which then sent this measured data to a computer. The Catman software was then used to assess and develop the force-time and displacement-time graphs. The displacement and force data obtained from the computer helped indicate the relationship between the pressure and the sinkage curves.

These steps were then repeated for $30 \mathrm{~cm}$ and $40 \mathrm{~cm}$ soil thickness levels, involving two initial bulk densities of 1.4 and $1.5 \mathrm{~g} / \mathrm{cm}^{3}$ and $1.3,1.4$, and $1.5 \mathrm{~g} / \mathrm{cm}^{3}$, respectively. Experiments were conducted to evaluate how the hard layer impacts the soil behavior and determine the zone in which the compaction and the hard layer interact.

\section{Deformation under Pressure Plate as a Function of Depth}

Deformation refers to compaction. The deformation in the plate sinkage test involved vertical and lateral compaction, along with soil movement under the plate [34]. There are typically two deformation zones in the field. The first is the build-up zone that has an increasing resistance, and the second is the stationary zone with constant resistance. To identify the soil density distribution in the deeper layers of sandy loam soil, Pillinger [33] used the cone penetrometer in a field. Pillinger also specified the two deformation zones and explained them in another study's results [24]. The pressure in the build-up zone can elevate to severe relative depth $\left(z_{0} / d\right)$. In the stationary zone, the pressure remains constant to an extent. The plat sinkage test can help observe this phenomenon. Figure 2 illustrates a plate sinkage test's schematic diagram. Once loading begins in the build-up zone, soil aggregates and particles rearrange while air becomes expelled, which increases the density of the dry bulk. Thus, sinkage mainly results from compaction below the plate. If the plate keeps sinking and the load is increased, then the soil immediately under the plate can no longer compact at the critical relative depth. Because of this, a conical mass is developed that moves by the plate and leads to lateral deformation and compaction; that is, sinkage is largely caused by soil becoming laterally displaced [34]. According to Sitkei et al. [24], however, if a hard layer is present at a certain depth under the footing (circular or rectangular), it can have a substantial effect on the pressure distribution, as well as the loadbearing capacity, of the soil. The hard layer mainly alters the soil's pressure distribution because the pressure is $60 \%$ greater compared to that in a homogeneous half-space. As a result, the interaction of the compact zone with the effect of a rigid layer increases compaction and pressure. Moreover, this pressure distribution can be altered as a function of relative depth. Figure 3 presents the assessment of Pillinger's measurements, where the critical relative depth as the soil density function was plotted. Their $\mathrm{z}_{\mathrm{o}} / \mathrm{d}$ measured $2-7 \mathrm{~cm}$ in depth. This value is based on the soil density and moisture content. As can be seen from Figure 3 , the critical relative depth $\left(z_{o} / d\right)$ strongly decreases at high moisture content levels, as the soil tends to exhibit plastic flow behavior. Hence, the experiments conducted in this study considered moisture content levels between $7 \%$ and $9 \%$. This study primarily aimed to determine the critical relative sinkage $\left(z_{0} / D\right)$, called the breaking point, by assessing the plate sinkage test's characteristics. 


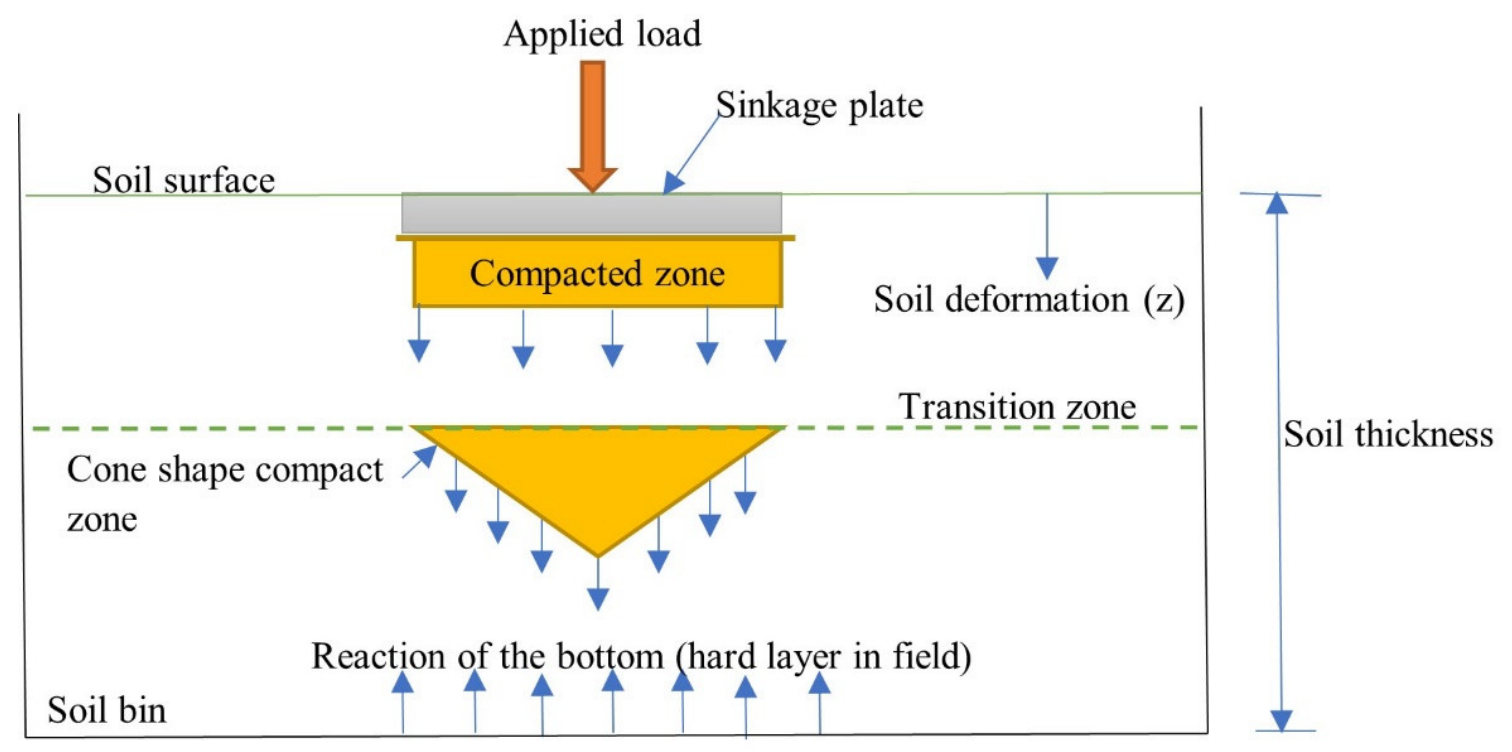

Figure 2. Schematic of the plate sinkage test.

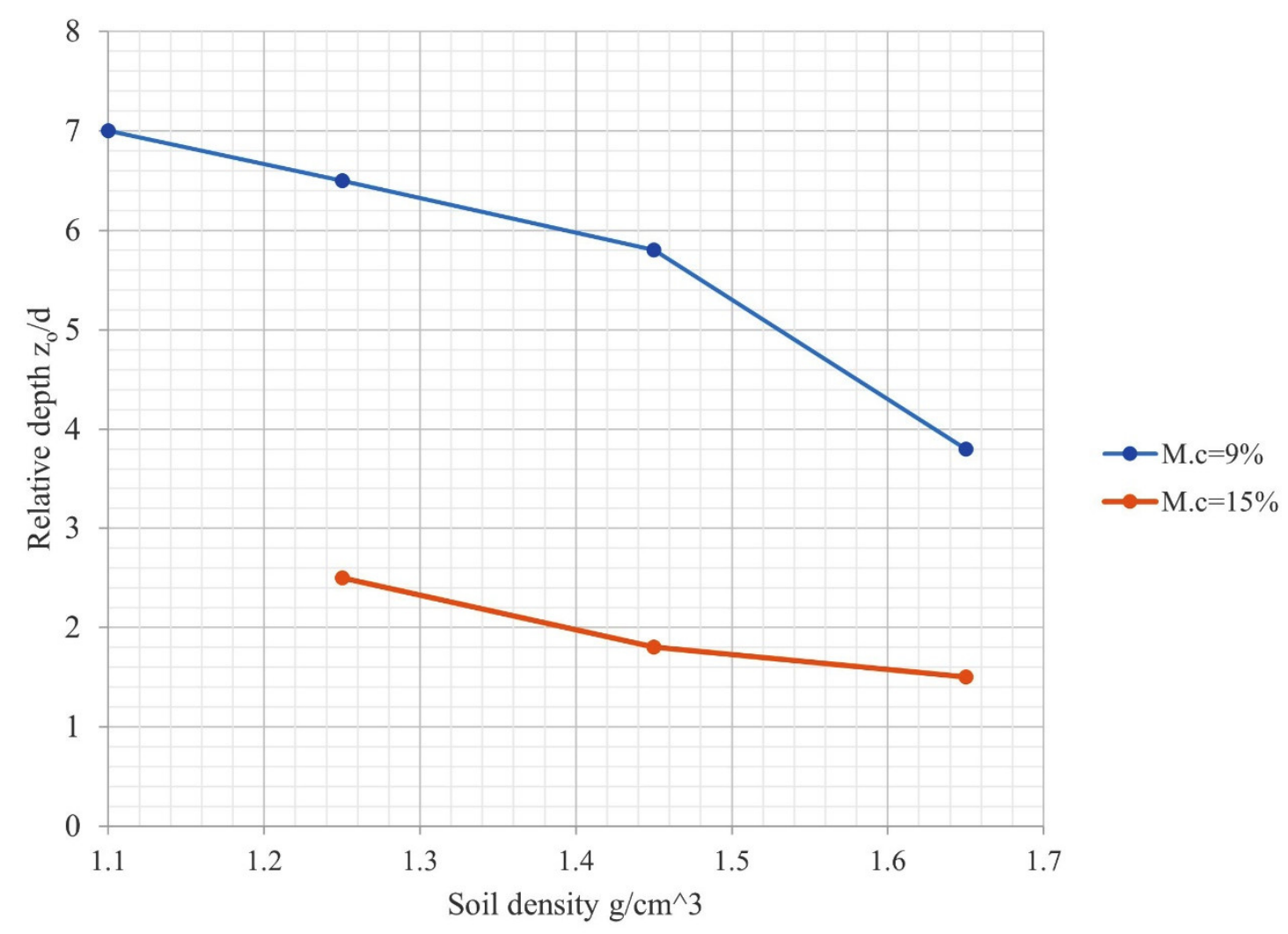

Figure 3. Relative depth $\left(z_{0} / d\right)$, with soil density at a moisture content level of $9 \%$ and $15 \%$ for a penetrometer cone of $1.6 \mathrm{~cm}$ in diameter.

Based on the experimental results, Equation (2) presents the breaking point, $\left(\mathrm{z}_{\mathrm{o}} / \mathrm{D}\right)$.

$$
\frac{\mathrm{z}_{\mathrm{o}}}{\mathrm{D}}-\frac{\mathrm{H}}{\mathrm{D}}=1.05-1.07
$$

where $z_{0}$ is the vertical deformation, $D$ is the sinkage plate diameter, and $H$ is the soil thickness. 
Table 2 presents the critical relative sinkage $\left(z_{0} / D\right)$ values of sinkage plates, gathered from the experiments involving varied soil thickness.

Table 2. Values of critical relative sinkage (breaking points), according to Equation (2).

\begin{tabular}{cccccc}
\hline $\begin{array}{c}\text { Soil Thickness } \\
\mathbf{H}[\mathrm{cm}]\end{array}$ & $\begin{array}{c}\text { Plate Diameter } \\
\mathbf{D}[\mathrm{cm}]\end{array}$ & $\mathbf{H} / \mathbf{D}$ & $\begin{array}{c}\mathbf{z}_{\mathbf{0}} / \mathrm{D}= \\
\mathrm{H} / \mathrm{D}-\mathbf{1 . 0 5}\end{array}$ & $\begin{array}{c}\mathbf{z}_{\mathbf{o}} / \mathrm{D}= \\
\mathbf{H} / \mathbf{D}-\mathbf{1 . 0 6}\end{array}$ & $\begin{array}{c}\mathbf{z}_{\mathbf{0}} / \mathrm{D}= \\
\mathbf{H} / \mathbf{D}-\mathbf{1 . 0 7}\end{array}$ \\
\hline 30 & 20 & 1.5 & 0.45 & 0.44 & 0.43 \\
40 & 20 & 2 & 0.95 & 0.94 & 0.93 \\
\hline
\end{tabular}

Figures 4 and 5 present the results of pressure-sinkage on a logarithmic scale for 30 and $40 \mathrm{~cm}$ soil thickness levels, respectively, considering a $20 \mathrm{~cm}$ sinkage plate diameter. The measurements were carried out at three initial bulk densities $(\rho)$ of $1.3,1.4$, and $1.5 \mathrm{~g} / \mathrm{cm}^{3}$. The curves clearly exhibited the transition zone before and after the breaking point for the plate sinkage test. As shown in the figures, the pressure-sinkage curves include two parts. The first part is prior to the breaking point that conveys the build-up zone. In this part of the curve, the plate acts upon a homogenous soil, where the effect of the hard layer does not exist and the increasing soil strength is not yet significant. The soil deformation increases constantly, and the soil under the plate behaves similarly to when it is in the infinite thickness (without a hard layer or a specific depth). The pressure continuously intensifies with the relative sinkage, and the relationship between them is almost linear. The second part is following the breaking point that indicates the compaction zone or the zone of the soil bin bottom (the hard layer in a field) effect. Here, the compaction, as well as the deformation, increases rapidly. Further, above the rigid layer, the pressure almost does not decrease, because this layer modifies the pressure distribution in the soil body. This extended portion from the transition zone to the specific depth has a varied load-bearing capacity.

Equation (1) can be used for the first part of the pressure-sinkage curve. A power regression analysis was carried out to determine the relationship between the applied pressure $(p)$ and the relative sinkage $\left(z_{0} / D\right)$ for both soil thickness levels with diverse densities, as per Equation (1). Table 3 presents the results. The data were fitted to the power model with a high coefficient of determination $\left(R^{2}\right)$.

Table 3. Parameters of Equation (1).

\begin{tabular}{ccccc}
\hline $\begin{array}{c}\text { Soil Thickness, } \\
\mathbf{H}[\mathbf{c m}]\end{array}$ & $\begin{array}{c}\text { Initial Bulk } \\
\text { Density }\left[\mathbf{g} / \mathbf{c m}^{\mathbf{3}}\right]\end{array}$ & $\mathbf{n}$ & $\begin{array}{c}\mathbf{k} \\
{\left[\mathbf{N} / \mathbf{c m}^{\mathbf{2}}\right]}\end{array}$ & $\begin{array}{c}\text { Coefficient of } \\
\text { Determination } \mathbf{( R}^{\mathbf{2}} \mathbf{)}\end{array}$ \\
\hline \multirow{3}{*}{30} & 1.3 & 0.7 & 30.28 & 0.99 \\
& 1.4 & 0.7 & 13.56 & 0.99 \\
40 & 1.5 & 0.7 & 17.96 & 0.98 \\
& 1.3 & 0.9 & 10.43 & 0.97 \\
& 1.4 & 0.8 & 29.80 & 0.98 \\
\hline
\end{tabular}

The exponent (n) represents the soil's deformation and compaction behavior, considering vertical loading. The soil's moisture content and particle size distribution have a major effect on this. The sinkage modulus (k) is primarily dependent on the soil type, moisture content, and density. As per [24], the average value of exponent (n) at the optimum moisture content level is 0.8 , which reduces as moisture content increases. The typical value of exponent (n) in the present study ranges from 0.7 to 0.9 , as shown in Table 3. 


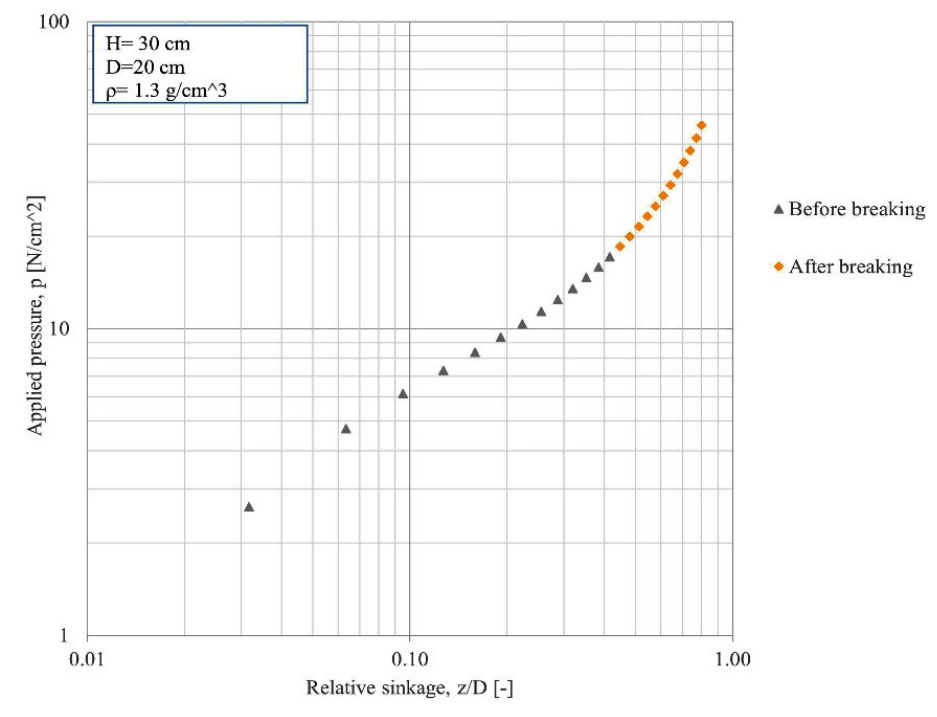

(a)

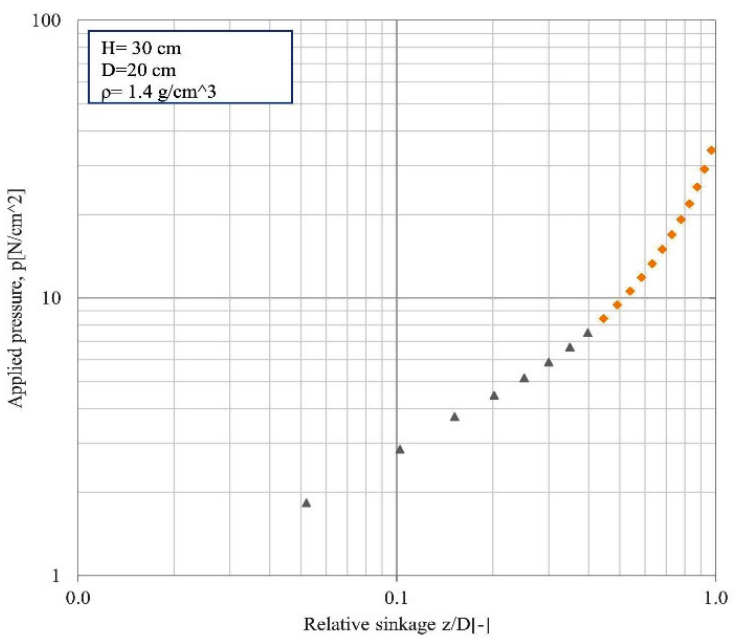

$\Delta$ Before breaking

- After breaking

(b)

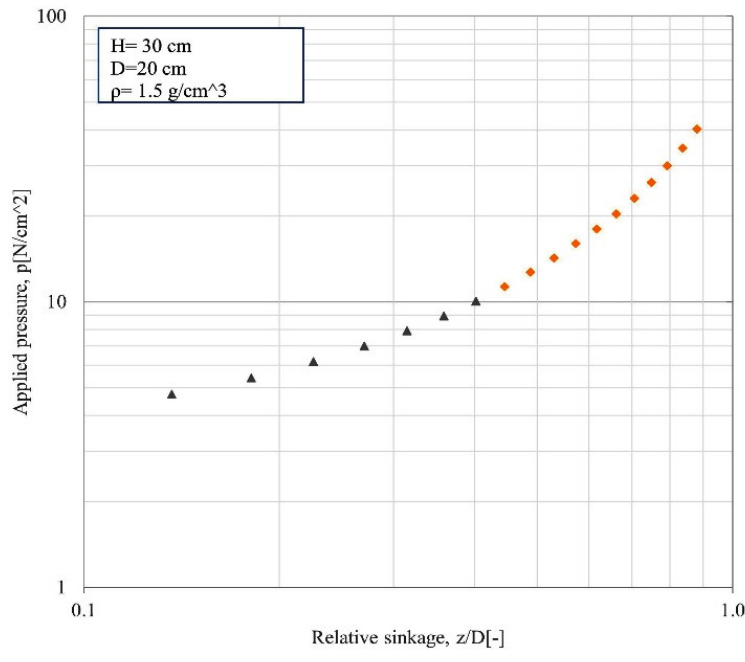

$\Delta$ Before breaking

- After breaking

(c)

Figure 4. Pressure-sinkage curves for a soil thickness level of $30 \mathrm{~cm}$ at bulk densities of (a) $1.3 \mathrm{~g} / \mathrm{cm}^{3}$, (b) $1.4 \mathrm{~g} / \mathrm{cm}^{3}$, and (c) $1.5 \mathrm{~g} / \mathrm{cm}^{3}$. 


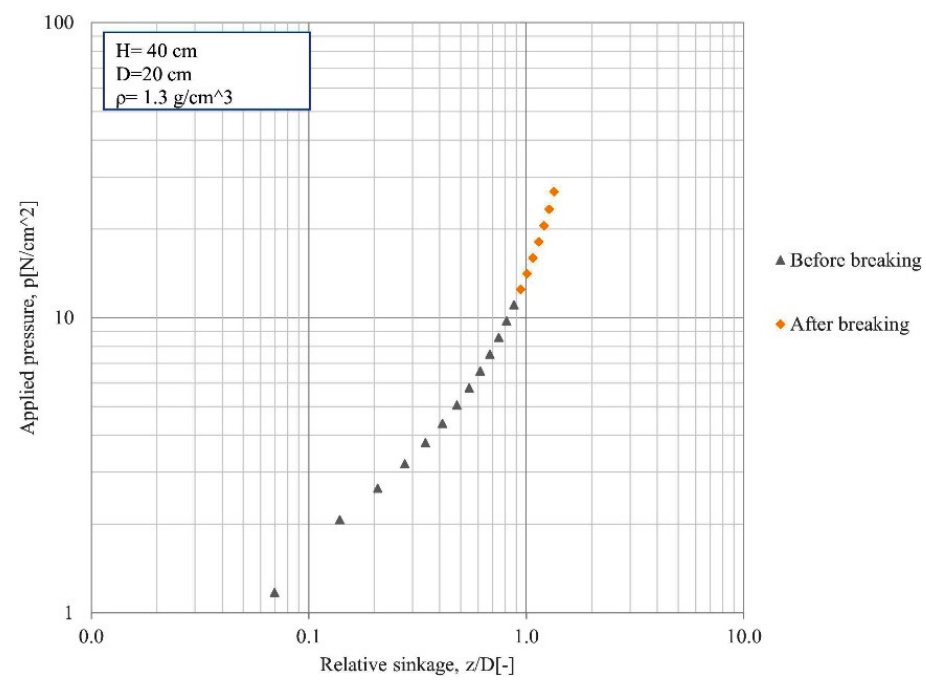

(a)

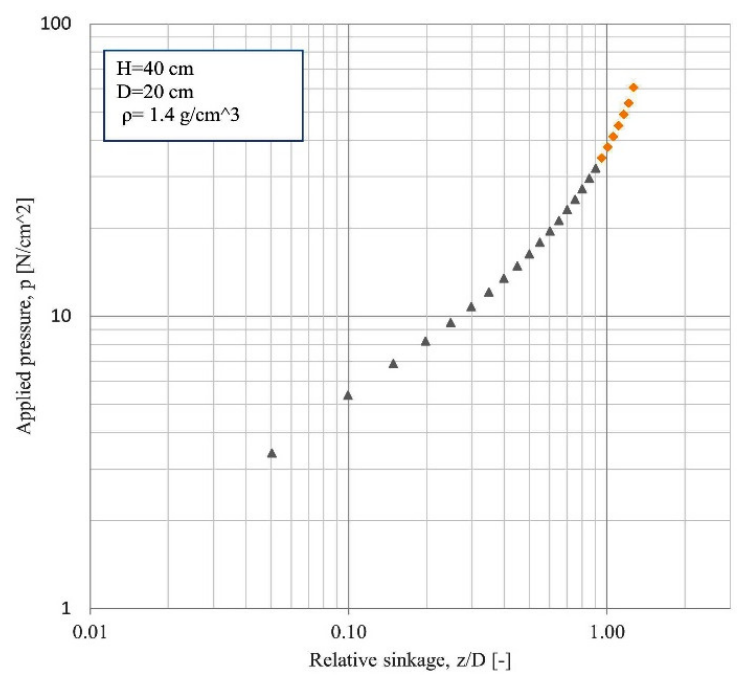

$\Delta$ Before breaking

- After breaking

(b)

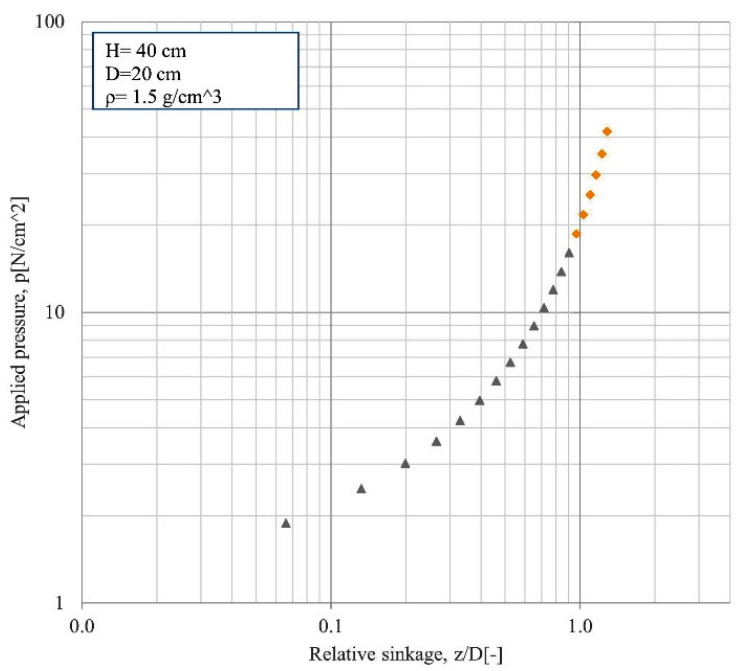

$\Delta$ Before breaking

- After breaking

(c)

Figure 5. Pressure-sinkage curves for a soil thickness level of $40 \mathrm{~cm}$ at bulk densities of (a) $1.3 \mathrm{~g} / \mathrm{cm}^{3}$, (b) $1.4 \mathrm{~g} / \mathrm{cm}^{3}$, and (c) $1.5 \mathrm{~g} / \mathrm{cm}^{3}$. 


\section{New Pressure-Sinkage Relationship Equation/Modified Sinkage Modulus (k)}

The conventional pressure-sinkage models can be used for homogenous, infinite soil thickness when an examination of the impact of the hard layer is not required. It was intended that certain proposals would be made for models that would consider the effect of the hard layer, but the models were too complicated and could not be applied. Hence, the present study's main aim is to improve a simple pressure-sinkage model (shown in Equation (1)) to assess the affection of the rigid layer. Most proposed pressure-sinkage models have tried to develop the sinkage modulus $(\mathrm{k})$ as functions concerning the plate dimensions or wheel dimensions. These models have also regarded the sinkage exponent as a constant soil parameter that is not impacted by other factors. The exponent (n), as well as the sinkage modulus (k), remain constant in the present study for the first part of the pressure-sinkage curve. These soil parameters, however, do not remain constant for the second part, because the bottom of the soil bin impacts the pressure distribution while increasing compaction. The compaction following the breaking point becomes a more exponential function, and hence, the exponent (n) is not constant. It is possible to improve Equation (1) by altering the two parameters so that the second part of the pressuresinkage curve can be more accurately characterized. As modifying both parameters is not effective, the sinkage modulus ( $\mathrm{k}$ ) can be modified using a simpler method. The exponent (n) characterizes the soil's deformation and compaction behavior under vertical loading. On the other hand, k indicates the soil's rigidity and is mainly influenced by the soil's properties. The experimental results concerning the two soil thickness levels at varied initial bulk densities show that a pressure-sinkage model is developed by presenting a new sinkage modulus concerning the affection of the soil's hard layer (Equations (3) and (4)):

$$
\begin{gathered}
\mathrm{p}=\mathrm{k}_{\mathrm{app}}\left(\frac{\mathrm{z}}{\mathrm{D}}\right)^{\mathrm{n}} \\
\mathrm{k}_{\mathrm{app}}=\mathrm{k}+\mathrm{B}\left(\mathrm{e}^{\mathrm{c}\left(\frac{\mathrm{z}}{\mathrm{D}}-\frac{\mathrm{z}_{0}}{\mathrm{D}}\right)}-1\right)
\end{gathered}
$$

where $\mathrm{k}_{\mathrm{app}}$ is the apparent sinkage modulus in unit $\mathrm{N} / \mathrm{cm}^{2}$, and $\mathrm{B}$ and $\mathrm{c}$ are constant. $\mathrm{z} / \mathrm{D}>\mathrm{z}_{\mathrm{o}} / \mathrm{D}$ (for the second part of the pressure-sinkage curve). The apparent sinkage modulus is equal to the sinkage modulus at $\mathrm{z} / \mathrm{D}<\mathrm{z}_{\mathrm{o}} / \mathrm{D}$ (for the first part of the pressuresinkage curve), as seen in Equation (5).

$$
\mathrm{k}_{\mathrm{app}}=\mathrm{k}
$$

$\Delta \mathrm{k}=\mathrm{k}_{\mathrm{app}}-\mathrm{k}$ and $\Delta \mathrm{z} / \mathrm{D}=\mathrm{z} / \mathrm{D}-\mathrm{z}_{\mathrm{o}} / \mathrm{D}$ for $\mathrm{z} / \mathrm{D}>\mathrm{z}_{\mathrm{o}} / \mathrm{D}$, by substituting these two terms in Equation (4), the following equation becomes:

$$
\Delta \mathrm{k}=\mathrm{B}\left(\mathrm{e}^{\mathrm{c} \Delta \mathrm{z}}-1\right)
$$

Considering the logarithm on both sides of Equation (6) leads to the new equation given below:

$$
\operatorname{In}\left(\frac{\Delta \mathrm{k}}{\mathrm{B}}+1\right)=\mathrm{c} \cdot \Delta\left(\frac{\mathrm{Z}}{\mathrm{D}}\right)
$$

To determine the constants B and c, two measured points on the pressure-sinkage curve can be used. The example given below presents the calculation involved. Table 4 presents the data of the example.

Table 4. The data of the example.

\begin{tabular}{cccccc}
\hline $\mathbf{z}_{\mathbf{0}} / \mathbf{D}$ & $\begin{array}{c}\text { Measured } \\
\mathbf{z} / \mathbf{D}\end{array}$ & $\Delta \mathbf{z} / \mathbf{D}=\mathbf{z} / \mathbf{D}-\mathbf{z}_{\mathbf{0}} / \mathbf{D}$ & $\begin{array}{c}\mathbf{k} \\
{\left[\mathbf{N} / \mathbf{c m}^{2}\right]}\end{array}$ & $\begin{array}{c}\text { Measured } \mathbf{k} \\
\text { or } \mathbf{k}_{\mathbf{a p p}}\end{array}$ & $\Delta \mathbf{k}=\mathbf{k}_{\text {app }}-\mathbf{k}$ \\
\hline 0.2 & 0.3 & 0.1 & 9 & 11 & 2 \\
& 0.6 & 0.4 & 9 & 24.5 & 15.5 \\
\hline
\end{tabular}


By substituting Table 4's data in Equation (7), the following two equations are provided:

$$
\begin{gathered}
\operatorname{In}\left(\frac{2}{B}+1\right)=0.1 \cdot \mathrm{c} \\
\operatorname{In}\left(\frac{15.5}{\mathrm{~B}}+1\right)=0.4 \cdot \mathrm{c}
\end{gathered}
$$

To determine the values of $B$ and $c$, the two equations form an implicit equation that can be solved using an implicit equation solver program. This program identified the constants as $\mathrm{B}=4.306$ and $\mathrm{c}=3.815$.

Figure 6 presents a model of the relationship between $\Delta \mathrm{k}$ and $\Delta(\mathrm{z} / \mathrm{D})$ that was suggested after several calculations of Equation (6) were completed to remove the calculation errors. It is seen that Equation (6) is flexible at different values of $B$ and $c$, but converging values were noticed at $\Delta(\mathrm{z} / \mathrm{D})=0.5$, where $\Delta \mathrm{k}=30\left[\mathrm{~N} / \mathrm{cm}^{2}\right]$. The range of $\mathrm{B}$ is $2-50$, while the range of $\mathrm{c}$ is $1-5$; hence, $\Delta(\mathrm{z} / \mathrm{D})=0.5$ is regarded as a fixed point to identify the optimum range for $B$ and c. Figure 7 shows the relationship between $B$ and $c$ that can help determine their range. Hence, Equation (6) was used to calculate the constant $B$ with a $\Delta \mathrm{k}$ range between 10 and 50 and a $c$ range between 1 and 5 . The $B$ and $c$ values are coherent for $\Delta \mathrm{k}(0.5)$ of 50,30 , and $20\left(\mathrm{~N} / \mathrm{cm}^{2}\right)$. In the present study, the optimum range for the constant $\mathrm{B}$ is between 10 and 20 , and between 1 and 3 for constant $\mathrm{c}$.

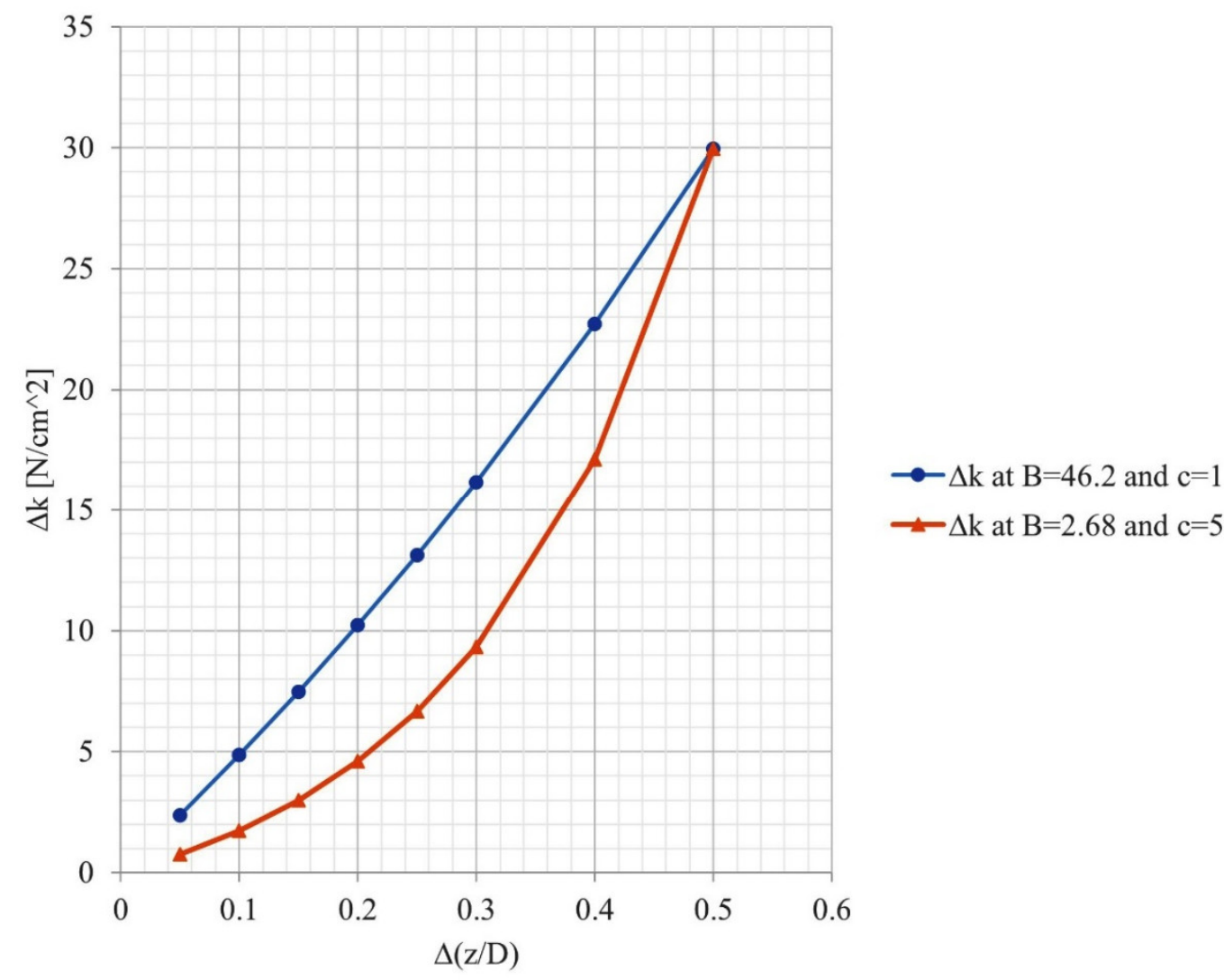

Figure 6. Model of the relationship of $\Delta \mathrm{k}$ versus $\Delta(\mathrm{z} / \mathrm{D})$. 


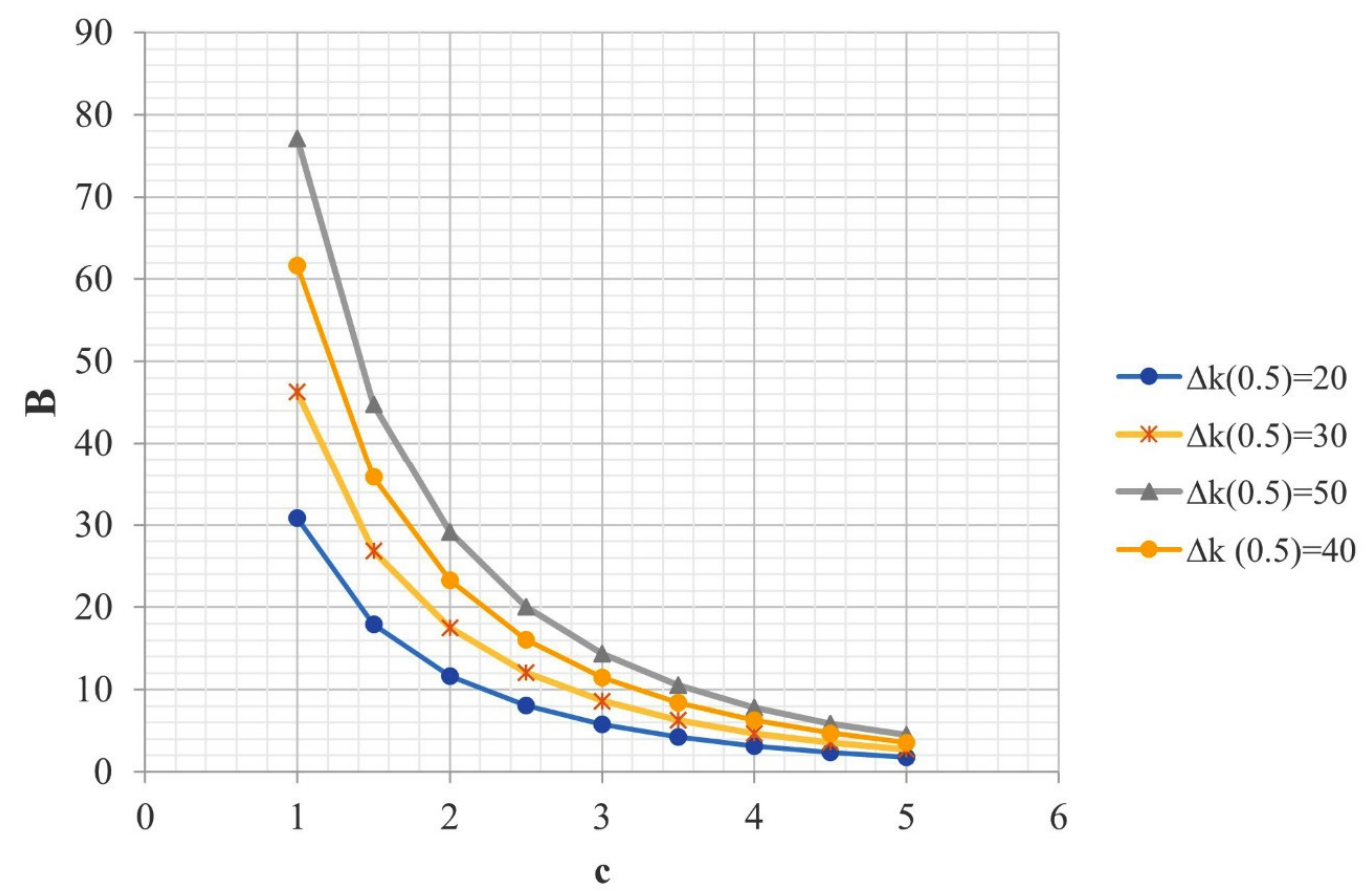

Figure 7. The relationship of constants B and c in Equation (6).

Experimental verification of the proposed sinkage modulus $\left(\mathrm{k}_{\mathrm{app}}\right)$ was conducted to determine the affection of a hard layer in the soil. Figures 8 and 9 show the pressuresinkage curve, load-bearing capacity factor $(\mathrm{k})$, and $\mathrm{k}_{\text {app }}$ curve results for the sinkage plate diameter of $20 \mathrm{~cm}$ at $30 \mathrm{~cm}$ and $40 \mathrm{~cm}$ soil thickness levels, respectively, with varied densities. The first part of the pressure-sinkage curve involved subjecting the build-up zone to Equation (1). To identify the equation's parameters, a regression analysis (Table 3) was used. In the first part of the curve (prior to the breaking point), where $k_{a p p}=k$ at $\mathrm{z} / \mathrm{D}<$ $\mathrm{z}_{\mathrm{o}} / \mathrm{D}$, no changes were seen in the sinkage exponent $(\mathrm{n})$ or the sinkage modulus $(\mathrm{k})$. There is an increase in pressure as a function of the relative sinkage as the logarithmic scale for showing the relation, and hence, the pressure and relative sinkage have a linear relationship. The load-carrying capacity factor ( $\mathrm{k}$ ) depends on density. Accordingly, its value increases with the rise in the soil density, with some abnormalities. These abnormalities occur because of the soil filling up in the bin in layers, as it is not easy to control all of the layers and ensure they have the same compaction and pressure distribution. The curve's second part shows the compact zone's interaction with the rigid layer. With increased deformation, the pressure also increases with relative sinkage. For this portion, the proposed Equation (4) was used, where $z / D>z_{0} / D$. Moreover, the figures show that the values of $k_{a p p}$ and the applied pressure are coherent. Hence, with increasing pressure, there is an increase in the sinkage modulus $\left(\mathrm{k}_{\mathrm{app}}\right)$, which leads to an increase in the soil's load-bearing capacity. 


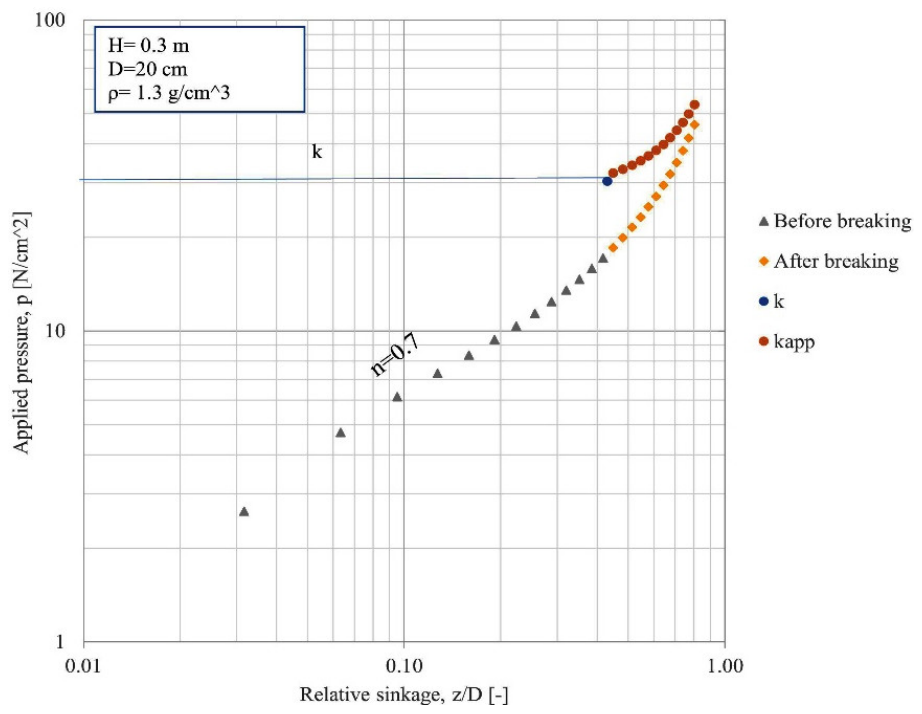

(a)

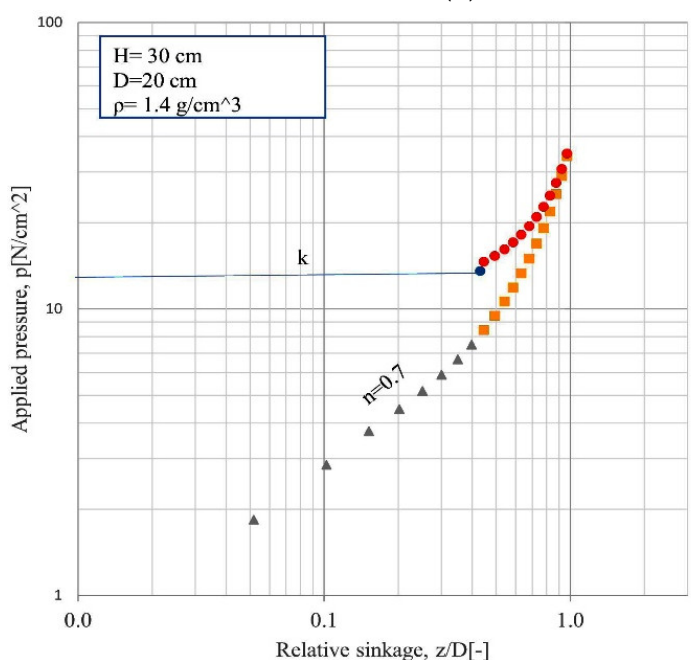

$\Delta$ Before breaking

= After breaking

- $\mathrm{k}$

• kapp

(b)

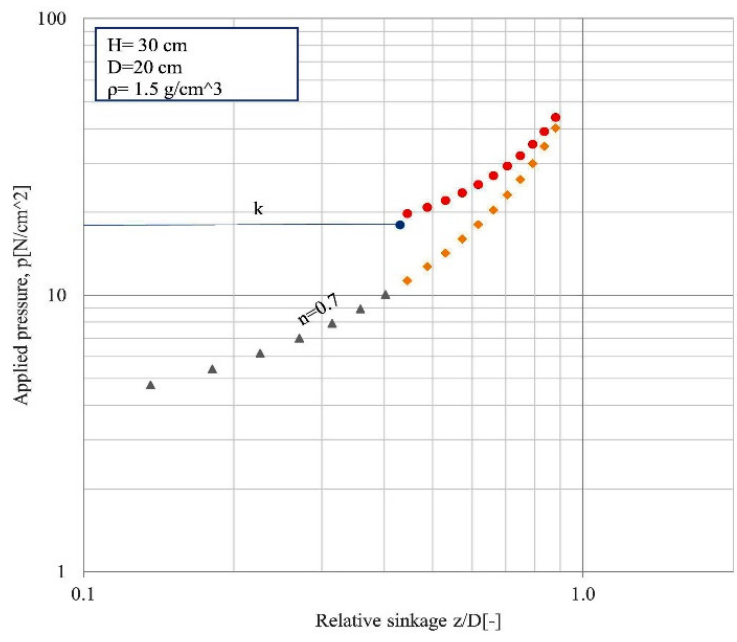

$\triangle$ Before breaking

- After breaking

- $\mathrm{k}$

- kapp

(c)

Figure 8. Pressure-sinkage curves with $\mathrm{k}_{\mathrm{app}}$ for a soil thickness level of $30 \mathrm{~cm}$ at bulk densities of (a) $1.3 \mathrm{~g} / \mathrm{cm}^{3}$, (b) $1.4 \mathrm{~g} / \mathrm{cm}^{3}$, and (c) $1.5 \mathrm{~g} / \mathrm{cm}^{3}$. 


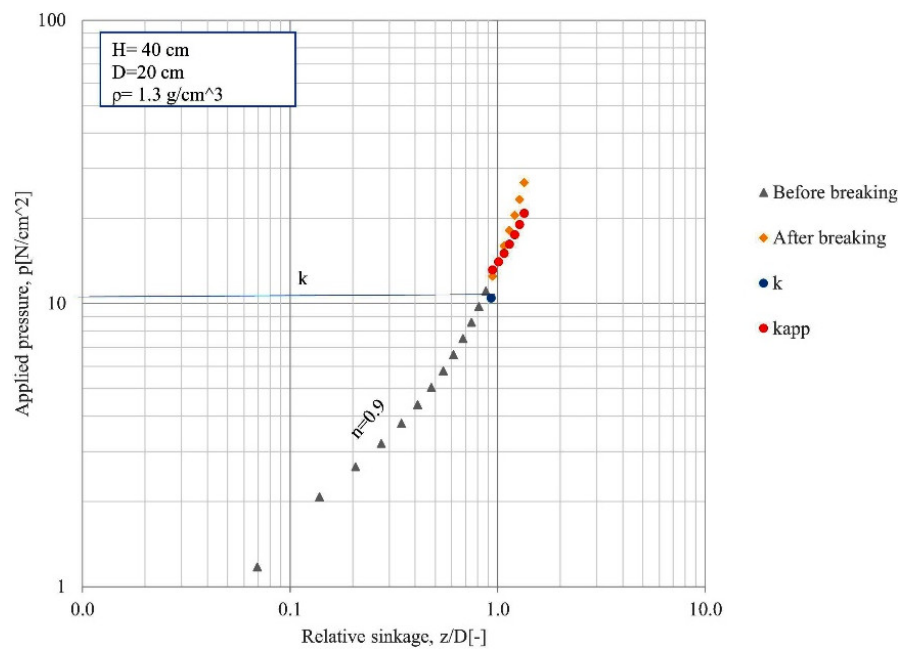

(a)

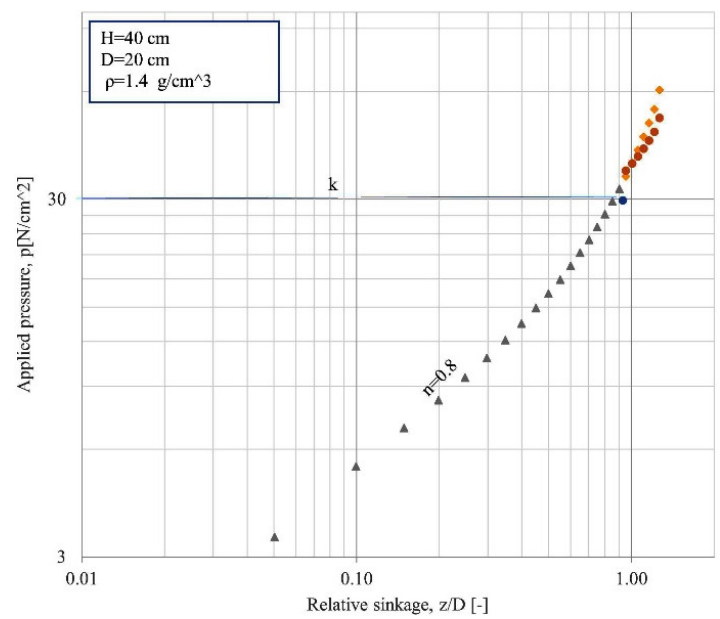

$\triangle$ Beforc breaking

- After breaking

$\bullet \mathrm{k}$

$\bullet$ kapp

(b)

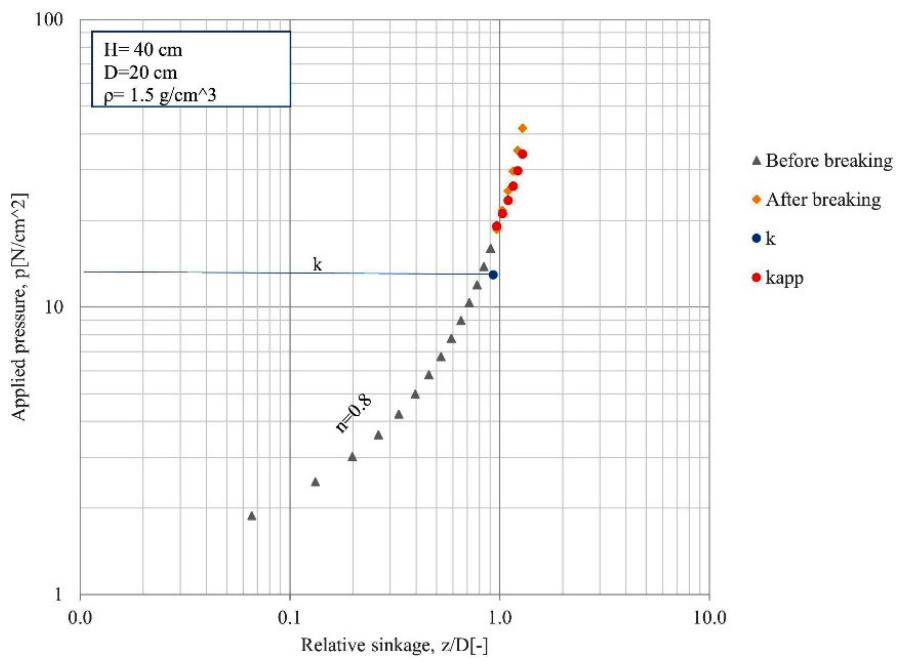

(c)

Figure 9. Pressure-sinkage curves with $\mathrm{k}_{\mathrm{app}}$ for a soil thickness level of $40 \mathrm{~cm}$ at bulk densities of (a) $1.3 \mathrm{~g} / \mathrm{cm}^{3}$, (b) $1.4 \mathrm{~g} / \mathrm{cm}^{3}$, and (c) $1.5 \mathrm{~g} / \mathrm{cm}^{3}$. 
Table 5 presents the values of $\mathrm{B}, \mathrm{c}, \Delta \mathrm{k}$, and $\mathrm{k}_{\mathrm{app}}$ at $\Delta(\mathrm{z} / \mathrm{D})=0.5$, in terms of two soil thickness levels at diverse densities. The table shows that there are anomalies in the outcomes of two of the tested conditions. First, in the case of the $30 \mathrm{~cm}$ soil thickness and the $1.3 \mathrm{~g} / \mathrm{cm}^{3}$ density, $\Delta \mathrm{k}$ and $\mathrm{k}_{\text {app }}$ should be below $17.2 \mathrm{~N} / \mathrm{cm}^{2}$ and $30.76 \mathrm{~N} / \mathrm{cm}^{2}$, respectively, which are the corresponding values of the $1.4 \mathrm{~g} / \mathrm{cm}^{3}$ density for the same thickness. However, the obtained results are $46.1 \mathrm{~N} / \mathrm{cm}^{2}$ and $76.4 \mathrm{~N} / \mathrm{cm}^{2}$, consecutively. Second, with the $40 \mathrm{~cm}$ soil thickness and the $1.4 \mathrm{~g} / \mathrm{cm}^{3}$ density, $\Delta \mathrm{k}$ and $\mathrm{k}_{\mathrm{app}}$ should be below 37.9 and $50.82 \mathrm{~N} / \mathrm{cm}^{2}$, respectively, which are the corresponding values of the $1.5 \mathrm{~g} / \mathrm{cm}^{3}$ density for the same thickness. Nevertheless, the acquired values are $40.6 \mathrm{~N} / \mathrm{cm}^{2}$ and $70.38 \mathrm{~N} / \mathrm{cm}^{2}$, consecutively. This irregularity occurred because the soil filled up as layers in the soil bin. Therefore, it was difficult to ensure that all layers were in the same compressed level and soil distribution.

Table 5. Values of $\mathrm{B}, \mathrm{c}, \Delta \mathrm{k}$, and $\mathrm{k}_{\mathrm{app}}$ at $\Delta(\mathrm{z} / \mathrm{D})=0.5$.

\begin{tabular}{cccccc}
\hline $\begin{array}{c}\text { Soil Thickness } \\
{[\mathbf{c m}]}\end{array}$ & $\begin{array}{c}\text { Density } \\
{\left[\mathbf{g} / \mathbf{c m}^{\mathbf{3}}\right]}\end{array}$ & $\begin{array}{c}\mathbf{\Delta k}(\mathbf{0 . 5}) \\
{\left[\mathbf{N} / \mathbf{c m}^{\mathbf{2}}\right]}\end{array}$ & $\begin{array}{c}\mathbf{k}_{\mathbf{a p p}} \mathbf{( 0 . 5 )} \\
{\left[\mathbf{N} / \mathbf{c m}^{\mathbf{2}}\right]}\end{array}$ & $\mathbf{c}$ \\
\hline \multirow{2}{*}{30} & 1.3 & 46.1 & 76.4 & 2.5 & 18.53 \\
& 1.4 & 17.2 & 30.76 & 2 & 10.33 \\
& 1.5 & 31.1 & 49.1 & 2.5 & 12.5 \\
40 & 1.3 & 19.27 & 29.70 & 1.5 & 12.2 \\
& 1.4 & 40.6 & 70.38 & 2.5 & 16.3 \\
\hline
\end{tabular}

To present the relationship between $\Delta \mathrm{k}$ and $\Delta(\mathrm{z} / \mathrm{D})$, Equation (6) used the values of B and c shown in Table 5. Figures 10 and 11 illustrate this relationship, along with the value of $\Delta \mathrm{k}$ at $\Delta(\mathrm{z} / \mathrm{D})=0.5$.

Most of the pressure-sinkage models in the literature have been applied to specify the behavior of homogeneous soils (without a hard layer). However, in the field, a vehicle usually operates in soils with a hard layer located at a certain depth. There have been some attempts to study the behavior of soils with a hard layer. Salman et al. [30] tested the hard layer's effect on sandy loam soil and noted that the hard layer raised the pressure and compaction, thus altering the soil behavior; however, this study did not improve a new pressure-sinkage model for studying the affection of a hard layer. Lyasko [25] developed an analytical pressure-sinkage model by examining invariant soil parameters that are not impacted by other factors, including the plates' dimensions. Nevertheless, this model is difficult to apply while studying the hard layer. Cerato and Lutenegger [35] modified the well-known Terzaghi bearing capacity equation by adjusting the shape factors first. Then, they improved the bearing capacity factor to account for the differences in the bearing capacity of the finite layer. However, this model is applicable for the foundation, not for the vehicle operating in a field. In contrast, the present study proposed a new pressure-sinkage relationship that can describe the soil's hard layer in a simple and general manner with meaningful parameters. 


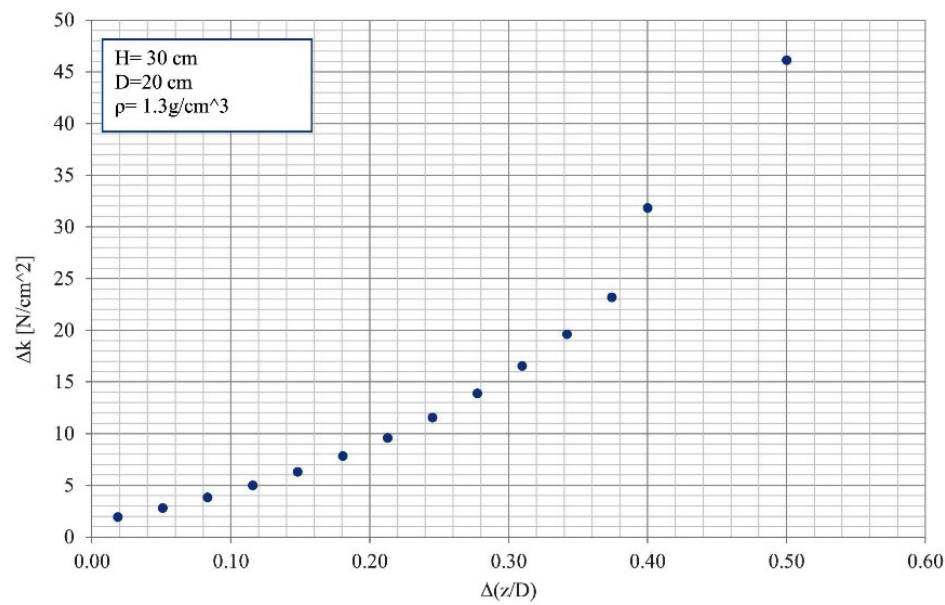

(a)

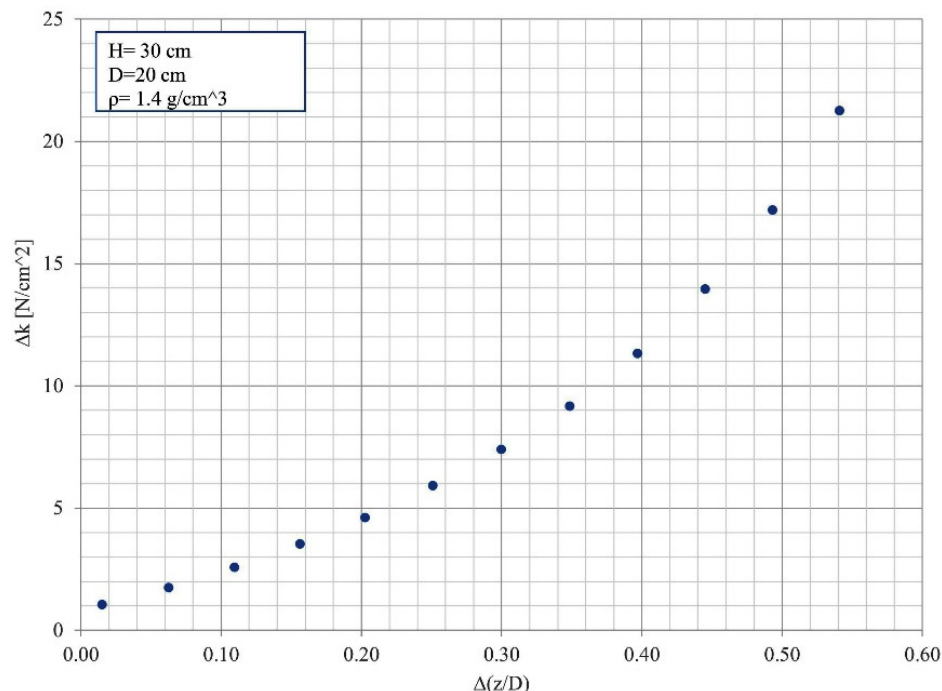

(b)

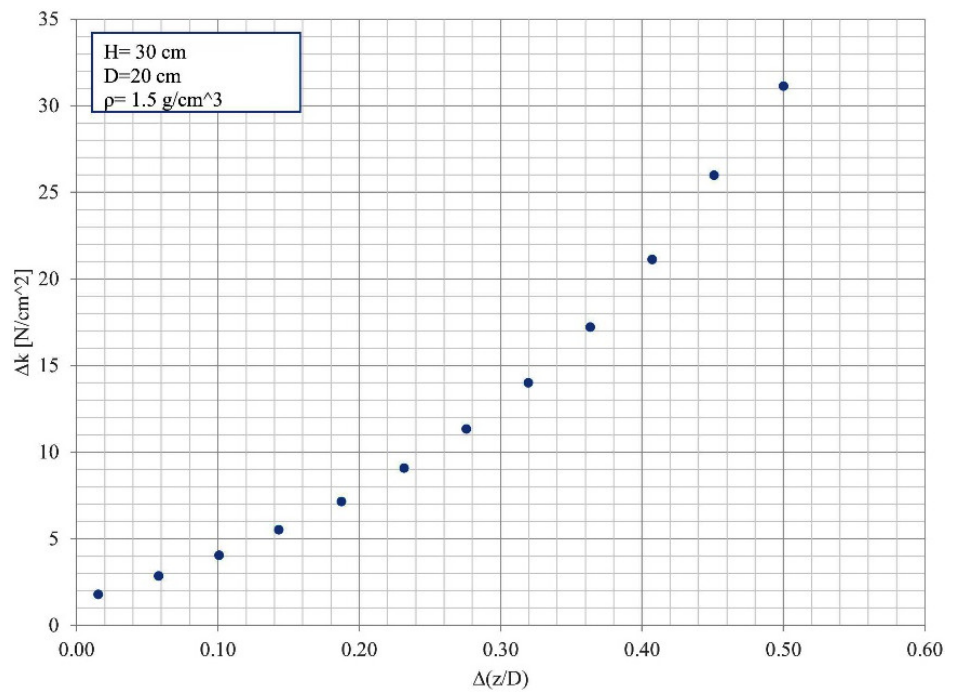

(c)

Figure 10. The relationship of $\Delta \mathrm{k}$ and $\Delta(\mathrm{z} / \mathrm{D})$ for a soil thickness level of $30 \mathrm{~cm}$ at bulk densities of (a) $1.3 \mathrm{~g} / \mathrm{cm}^{3}$, (b) $1.4 \mathrm{~g} / \mathrm{cm}^{3}$, and (c) $1.5 \mathrm{~g} / \mathrm{cm}^{3}$. 


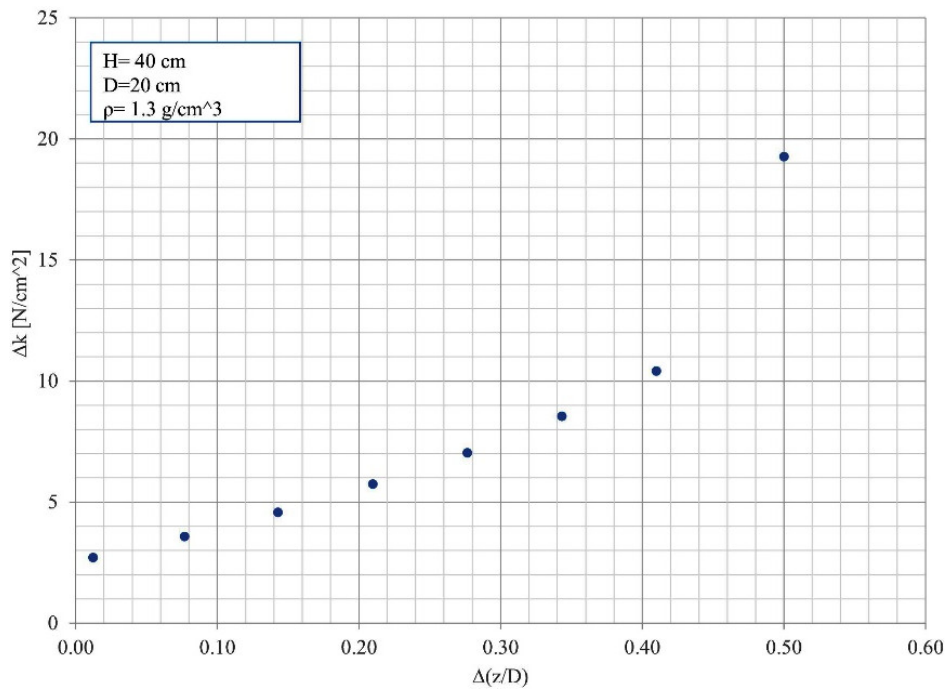

(a)

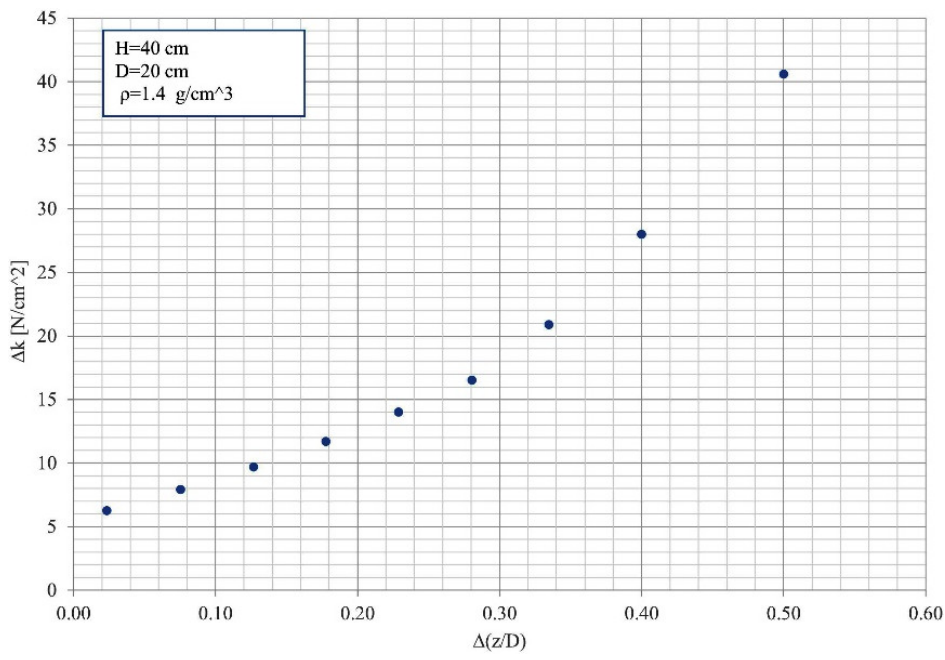

(b)

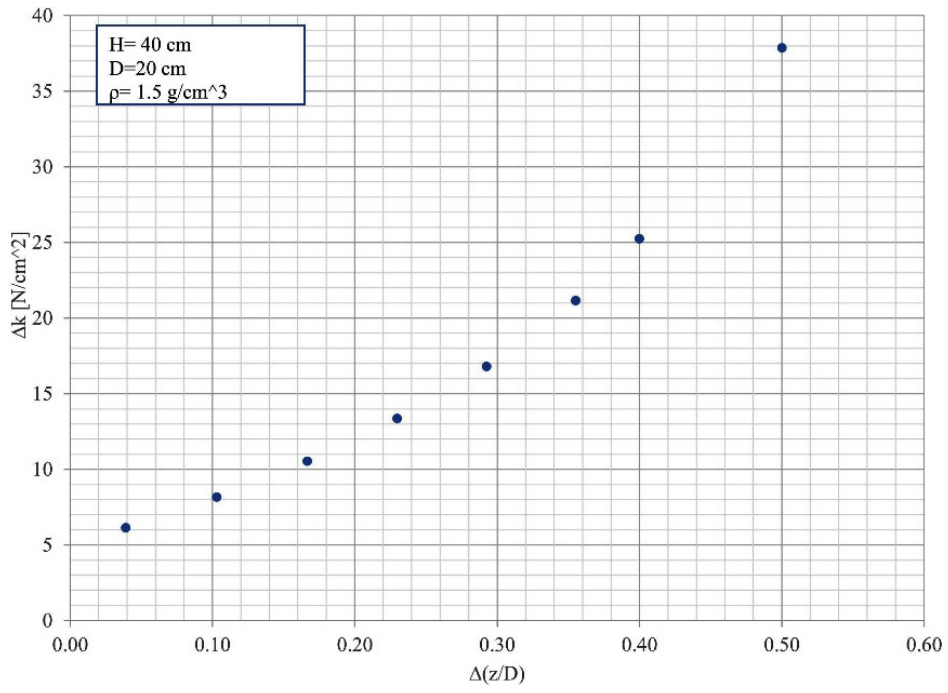

(c)

Figure 11. The relationship of $\Delta \mathrm{k}$ and $\Delta(\mathrm{z} / \mathrm{D})$ for a soil thickness level of $40 \mathrm{~cm}$ at bulk densities of (a) $1.3 \mathrm{~g} / \mathrm{cm}^{3}$, (b) $1.4 \mathrm{~g} / \mathrm{cm}^{3}$, and (c) $1.5 \mathrm{~g} / \mathrm{cm}^{3}$. 


\section{Conclusions}

This study examined the conventional pressure-sinkage models' limitations when assessing the effect of the rigid layer in soil. To accomplish this, an empirical investigation was conducted to determine the hard layer's impact on the pressure-sinkage relationship for plate sinkage that has a diameter similar to the vehicle tier. The study also explored the interaction zone between the rigid and compacted layers, and determined the critical relative sinkage $\left(\mathrm{z}_{\mathrm{o}} / \mathrm{D}\right)$, which is also called the breaking point. The soil deformation under the plate was also identified. Two zones were outlined by the pressure-sinkage curves, which are the build-up zone with constant deformation and the other zone following the breaking point, which has exponential and non-constant deformation. The study further discussed modifying a simple conventional pressure-sinkage model to examine the hard layer. To accomplish this, a model parameter was improved upon, which is the sinkage modulus ( $\mathrm{k}$; the load-bearing capacity factor), resulting in a new parameter, $\mathrm{k}_{\text {app }}$ (the apparent sinkage modulus). According to the results, the rigid layer increased the compaction, thereby increasing the pressure and $k_{a p p}$. In the $k_{a p p}$ equation, constants $B$ and $\mathrm{c}$ were measured from two points on the experimental pressure-sinkage curve. The equation was further simplified both to make it implicit and to ensure that it could be solved numerically. To avoid calculation errors, the $\Delta \mathrm{k}$ model with $\Delta(\mathrm{z} / \mathrm{D})$ was put forth In this model, different $B$ and $\mathrm{c}$ values were used to determine coherent values of $\Delta \mathrm{k}$ at $\Delta(\mathrm{z} / \mathrm{D})=0.5$. Hence, this point was selected as a fixed point for determining the best range of $B$ and c constants. A model used to determine the relationship between $B$ and C was also presented, which showed coherent values regarding the constants at $\Delta \mathrm{k}=20$, 30 , and $50 \mathrm{~N} / \mathrm{cm}^{2}$. The optimum range for $\mathrm{B}$ was thus determined to be between 10 and 20 , and between 1 and 3 for $c$. The present model of the pressure-sinkage equation was thus found to reflect the rigid layer effect in soil with high fidelity through the new sinkage modulus equation.

In the current study, the new modification of the load-bearing capacity factor $(\mathrm{k})$ and the new pressure-sinkage model have been proposed and have been used to represent the affection of a hard layer in the soil. In future work, the authors plan to generalize the pressure-sinkage model and transform it into a full dimensionless form while considering the effect of the soil density and the finite depth.

Author Contributions: Conceptualization, N.D.S.; methodology, N.D.S. and G.P.; validation, N.D.S., G.P., and M.M.H.; formal analysis, N.D.S. and G.P.; investigation, N.D.S., G.P., and M.M.H.; resources, P.K. and G.P.; data curation, N.D.S. and G.P.; writing—original draft preparation, N.D.S.; writingreview and editing, N.D.S. and M.M.H.; visualization, N.D.S.; supervision, P.K.; funding acquisition, P.K. All authors have read and agreed to the published version of the manuscript.

Funding: This research received no external funding.

Institutional Review Board Statement: Not applicable.

Informed Consent Statement: Not applicable.

Acknowledgments: This work was supported by the Stipendium Hungaricum Programme and by the Mechanical Engineering Doctoral School, Szent István Campus, MATE University, Gödöllő, Hungary.

Conflicts of Interest: The authors declare no conflict of interest.

\section{References}

1. Jang, G.; Lee, S.; Lee, K. Discrete element method for the characterization of soil properties in Plate-Sinkage tests. J. Mech. Sci. Technol. 2016, 30, 2743-2751. [CrossRef]

2. Li, B.; Yuan, H. Research on dynamic characteristics and reliability of a new heavy duty tractor. J. Adv. Mech. Des. Syst. Manuf. 2019, 13, JAMDSM0010. [CrossRef]

3. Kiss, P.; Laib, L. Energy Determination of Vertical Soil Deformation in Case of Tractor Wheels and Soft Soil. In Proceedings of the 15th International ISTVS Conference, Hayama, Japan, 25-29 September 2005; pp. 315-322.

4. Kiss, P. Rolling Radii of a Pneumatic Tyre on Deformable Soil. Biosyst. Eng. 2003, 85, 153-161. [CrossRef] 
5. Müller, L.; Lipiec, J.; Kornecki, T.S.; Gebhardt, S. Trafficability and Workability of Soils; Springer: Dordrecht, The Netherlands, 2011; pp. 912-924.

6. Taghavifar, H.; Mardani, A. Off-Road Vehicle Dynamics. In Studies in Systems, Decision and Control; Springer International Publishing: Cham, Switzerland, 2017; Volume 70, ISBN 978-3-319-42519-1.

7. Ding, L.; Gao, H.; Deng, Z.; Li, Y.; Liu, G. New perspective on characterizing pressure-sinkage relationship of terrains for estimating interaction mechanics. J. Terramechanics 2014, 52, 57-76. [CrossRef]

8. Wong, J.Y. Terramechanics and Off-Road Vehicle Engineering, 2nd ed.; Elsevier Ltd: Oxford, UK, 2010; ISBN 9780750685610.

9. Bekker, M.G. Introduction to Terrain-Vehicle Systems, 1st ed.; University of Michigan Press: Ann Arbor, MI, USA, 1969.

10. Chen, D.; Hou, L.; Bu, X.; Chen, Y. A piecewise bearing capacity method of unstructured terrain considering characteristics of soil mechanic and wheel geometry. J. Terramechanics 2020, 89, 13-20. [CrossRef]

11. Wang, M.; Wang, X.; Sun, Y.; Gu, Z. Tractive performance evaluation of seafloor tracked trencher based on laboratory mechanical measurements. Int. J. Nav. Archit. Ocean Eng. 2016, 8, 177-187. [CrossRef]

12. Laib, L.; Máthé, L.; Kiss, P. Computation of Run-Off-Road Vehicle Velocity by Simulation. In Proceedings of the 17th International Conference of the ISTVS, Blacksburg, VA, USA, 18-22 November 2011; pp. 289-294.

13. Pillinger, G.; Kiss, P. Modeling the Energetics of Tire-Soil Interaction. In Proceedings of the 17th International Conference of the ISTVS, Blacksburg, VA, USA, 18-22 November 2011.

14. Gao, Y. Contemporary Planetary Robotics; Wiley-VCH: Weinheim, Germany, 2016; ISBN 9783527413256.

15. Yang, C.; Yang, G.; Liu, Z.; Chen, H.; Zhao, Y. A method for deducing pressure-sinkage of tracked vehicle in rough terrain considering moisture and sinkage speed. J. Terramechanics 2018, 79, 99-113. [CrossRef]

16. He, R.; Sandu, C.; Khan, A.K.; Guthrie, A.G.; Schalk Els, P.; Hamersma, H.A. Review of terramechanics models and their applicability to real-time applications. J. Terramechanics 2019, 81, 3-22. [CrossRef]

17. Edwards, M.B.; Dewoolkar, M.M.; Huston, D.R.; Creager, C. Bevameter testing on simulant Fillite for planetary rover mobility applications. J. Terramechanics 2017, 70, 13-26. [CrossRef]

18. Meirion-Griffith, G.; Spenko, M. A pressure-sinkage model for small-diameter wheels on compactive, deformable terrain. J. Terramechanics 2013, 50,37-44. [CrossRef]

19. Meirion-Griffith, G.; Spenko, M. A modified pressure-sinkage model for small, rigid wheels on deformable terrains. J. Terramechanics 2011, 48, 149-155. [CrossRef]

20. Gotteland, P.; Benoit, O. Sinkage tests for mobility study, modelling and experimental validation. J. Terramechanics 2006, 43, 451-467. [CrossRef]

21. Ding, L.; Yang, H.; Gao, H.; Li, N.; Deng, Z.; Guo, J.; Li, N. Terramechanics-based modeling of sinkage and moment for in-situ steering wheels of mobile robots on deformable terrain. Mech. Mach. Theory 2017, 116, 14-33. [CrossRef]

22. Bekker, M.G. Theory of Land Locomotion; University of Michigan Press: Ann Arbor, MI, USA, 1956; ISBN 9780472750207.

23. Reece, A.R. Principles of soil-vehicle mechanics. Proc. Inst. Mech. Eng. 1965, 180, 45-66. [CrossRef]

24. Sitkei, G.; Pillinger, G.; Máthé, L.; Gurmai, L.; Kiss, P. Methods for generalization of experimental results in terramechanics. J. Terramechanics 2019, 81, 23-34. [CrossRef]

25. Lyasko, M. LSA model for sinkage predictions. J. Terramechanics 2010, 47, 1-19. [CrossRef]

26. Sitkei, G. Sinkage and rolling resistance of wheels. Prog. Agric. Eng. Sci. 2015, 11, 85-94. [CrossRef]

27. Ageikin, J.S. Off-The-Road Mobility of Automobiles; Amerind Publish Co.: New Delhi, India, 1987.

28. Ageikin, J.S. Off-the-road Wheeled and Combined Traction Devices: Theory and Calculation; Amerind Publish Co.: New Delhi, India, 1987.

29. Egorov, K.E. Deformation of a foundation bed of finite thickness. Soil Mech. Russ. Res. Inst. Found. 1961, 43.

30. Salman, N.D.; Pillinger, G.; Kiss, P. Soil behaviour under load in case of finite thickness. Int. Rev. Appl. Sci. Eng. 2021, 12, 29-33. [CrossRef]

31. Salman, N.D.; Pillinger, G.; Hanon, M.M.; Kiss, P. Design and performance evaluation of bevameter equipment. J. Adv. Mech. Des. Syst. Manuf. 2020, 14, JAMDSM0084. [CrossRef]

32. Máthé, L. Analysis of the Motion of Vehicles Running onto Terrain; Szent Istvan University: Gödöllő, Hungary, 2014.

33. Pillinger, G. Deformation and Damping of Soil under Tire; Szent Istvan University: Gödöllő, Hungary, 2016.

34. Earl, R. Assessment of the Behaviour of Field Soils during Compression. J. Agric. Eng. Res. 1997, 68, 147-157. [CrossRef]

35. Cerato, A.B.; Lutenegger, A.J. Bearing Capacity of Square and Circular Footings on a Finite Layer of Granular Soil Underlain by a Rigid Base. J. Geotech. Geoenvironm. Eng. 2006, 132, 1496-1501. [CrossRef] 